\title{
Population Variation of Apple Scab (Venturia inaequalis) Isolates from Asia and Europe
}

Xiangming Xu, East Malling Research, East Malling, West Malling, Kent, UK; Jiarong Yang, Institute of Crop Protection, Northwest Sci-Tech University of Agriculture and Forestry, Yangling, Shaanxi Province, PR China; Vijay Thakur, Dr YS Parmar University of Horticulture \& Forestry, Regional Horticultural Research Station, Mashobra, Shimla-171007 (HP), India; Anthony Roberts, East Malling Research, New Road, East Malling, Kent ME19 6BJ, UK; Dez J. Barbara, Warwick HRI, Wellesbourne, Warwick CV35 9EF, UK

\begin{abstract}
Xu, X., Yang, J., Thakur, V., Roberts, A., and Barbara, D. J. 2008. Population variation of apple scab (Venturia inaequalis) isolates from Asia and Europe. Plant Dis. 92:247-252.

Apple scab, caused by Venturia inaequalis, is one of the most of damaging diseases worldwide on apple and currently is managed mainly by scheduled applications of fungicides. Understanding pathogen population structure is important for breeding and deployment of resistant cultivars. Isolates of $V$. inaequalis were sampled from a number of cultivars in China, India, and the United Kingdom to estimate differences in pathogen populations. Amplified fragment length polymorphism (AFLP) markers were used to genotype isolates, mostly from China and the United Kingdom. The AFLP data indicated that, overall, there were significant differences in $V$. inaequalis populations from China and the United Kingdom. Within China, there was no significant differentiation associated with their geographical or cultivar origins. In contrast, populations from four cultivars in two U.K. orchards (monoculture of Gala and a mixture orchard of Bramley, Cox, and Worcester) differed significantly. Furthermore, populations from Gala and Worcester were more homogenous than expected but those from Cox were more diverse than expected. In total, 80 isolates were selected randomly from three countries for virulence testing: 20 from the United Kingdom (10 from Gala and 10 from Cox), 30 from China (10 from Gala, 10 from Fuji, and 10 from Qingquan), and 30 from India (10 from Gala, 10 from Golden Delicious, and 10 from Black Ben Davis); of these 80 isolates, 41, 47, and 59 were inoculated against each of these cultivars in the United Kingdom, India, and China, respectively. The two local cultivars from India (Black Ben Davis) and the United Kingdom (Cox) were more resistant against nonindigenous isolates, particularly those from China, than they were against indigenous isolates; the Chinese local cultivar (Qingguan) showed a higher general level of resistance against isolates regardless of their origin.
\end{abstract}

Venturia inaequalis causes annual epidemics of apple scab, which vary in severity, largely according to weather conditions (19). An annual sexual phase associated with the overwintering of the fungus on leaf litter leads to epidemics of an asexual haploid stage during the spring and summer. High-quality fruit standards require very high levels of control, particularly in fruit for fresh market sales. Although adopting a decision-based control strategy can result in a significant reduction of fungicide input (3), breeding cultivars with durable resistance remains the ultimate objective for effective scab control.

Several major genes for resistance $(R$ genes) against $V$. inaequalis are known (33), mostly originating from small-fruited Asiatic Malus spp. It generally is assumed that there are no major $R$ genes present in

Corresponding author: $\mathrm{X} . \mathrm{Xu}$

E-mail: xiangming.xu@emr.ac.uk

Accepted for publication 14 September 2007.

doi:10.1094/PDIS-92-2-0247

(C) 2008 The American Phytopathological Society the cultivated Malus $\times$ domestica, but two major $R$ genes recently were discovered in Malus $\times$ domestica: $V g$ from $\mathrm{cv}$. Golden Delicious (2) and $V d$ from cv. Durello di Forli (28). Eight major physiological races of apple scab have been reported, most of which correspond to major $R$ genes on a gene-for-gene relationship (11). Currently, only the $V f$ gene from Malus floribunda has been incorporated into commercial cultivars and is the most studied resistance gene in apple $(2,9,23,32,34,35)$. The $V f$ resistance has been overcome in several locations $(22,26)$. Although research on host-pathogen interactions on apple scab has focused so far on major $R$ genes, there is some evidence that polygenic resistance against $V$. inaequalis also occurs in apple cultivars $(6,7,15,18,19)$. Several recent studies showed that susceptible cultivars may carry some genes for resistance to $V$. inaequalis as well $(14,15,27)$. In addition to broad-spectrum polygenic resistance, polygenic yet isolate-specific resistance has been identified in cultivars with partial resistance to scab (6).

One key piece of knowledge necessary for breeding cultivars with durable resistance and the effective deployment of such cultivars is the understanding of the virulence structures in fungal populations and the extent to which evolutionary forces may alter the virulence structure. Currently, there is limited knowledge concerning the differences in population structure of $V$. inaequalis among cultivars within a region, regions within a country, countries in a continent, and among continents. Population variability of $V$. inaequalis in Europe (4 populations from Switzerland and 11 from five other European countries) have been investigated using random amplified polymorphic DNA (RAPD) and polymerase chain reaction-restriction fragment length polymorphism (PCRRFLP) markers $(30,31)$. Genetic diversity within populations was high and differentiation among populations was lower. The extent of population differentiation increased with increasing geographic distance.

Knowledge obtained from neutral molecular markers can be used to infer the underlying evolutionary forces acting on the population and, hence, to estimate the likely spread of new virulence traits into the population (i.e., to estimate the durability of resistance genes). The accuracy of such a prediction would be increased if neutral molecular data were supplemented with knowledge of fungal virulence genes. Research on $V$. inaequalis has focused on identifying resistance sources, elucidating and pyramiding $R$ genes, and practical disease management $(11,20,21)$.

In this article, we report studies on variability between $V$. inaequalis populations sampled from several cultivars in the United Kingdom, China, and India. Amplified fragment length polymorphism (AFLP) markers were used to quantify fungal population variation in relation to geographical origin (China and the United Kingdom) and host cultivars. Ten isolates from each of two (United Kingdom) and three (China and India) cultivars were selected and inoculated against each of these cultivars in each country to investigate their virulence characteristics. In addition, many European isolates of known race types were included in AFLP screening to determine whether there is any similarity between scab races and other isolates sampled from China and the United Kingdom. 


\section{MATERIALS AND METHODS}

Sampling sites and isolate collection. Most isolates for AFLP screening were collected in China and the United Kingdom, with a few from India (Table 1). In China, isolates were from monoculture orchards in two counties (Xingping and Xunyi, approximately $100 \mathrm{~km}$ apart), Shaanxi Province; within each county, sampled orchards were less than $1,000 \mathrm{~m}$ apart. In India, sampling was conducted in the Shimla and Kullu Valley regions (approximately $120 \mathrm{~km}$ apart). In the United Kingdom, isolates were sampled from a mixed orchard in Herefordshire (cvs. Cox, Bramley, and Worcester) and a monoculture orchard of cv. Gala in Kent; these two orchards were approximately $250 \mathrm{~km}$ apart. The three cultivars in the mixed orchard were planted in rows adjacent to each other. Sampling in India and China was carried out in 2002 and 2003; and, in the United Kingdom, in 2001 on Cox, 2002 on Gala, and 2003 on Bramley and Worcester. In addition, 17 European isolates of known scab races, 12 of which were provided by Dr. Luciana Parisi of INRA, France, were included in AFLP screening.

Leaves with freshly sporulating, discrete lesions were collected from orchards in late spring or early summer. These colonies most likely resulted from primary infections by ascospores rather than from secondary infections by conidia. A cork borer $(5 \mathrm{~mm})$ was used to cut a disc with a lesion from each leaf. Each disc was transferred to a microcentrifuge tube, air dried at room temperature, and stored at $-20^{\circ} \mathrm{C}$. Water agar (15 $\left.\mathrm{g} \mathrm{liter}^{-1}\right)$ amended with rifamycin (50 mg liter ${ }^{-1}$ ) was used to obtain single-spore isolates. An infected leaf disc was added to distilled water and agitated thoroughly; conidial concentration was adjusted to $8 \times 10^{3}$ conidia $\mathrm{ml}^{-1}$. Approximately $200 \mu \mathrm{l}$ of suspension then was

Table 1. Number of isolates of Venturia inaequalis included in amplified fragment length polymorphism analysis and their origin

\begin{tabular}{|c|c|c|c|c|c|}
\hline \multirow[b]{2}{*}{ Cultivar } & \multirow[b]{2}{*}{ United Kingdom } & \multirow[b]{2}{*}{ India } & \multicolumn{2}{|c|}{ China } & \multirow[b]{2}{*}{ France } \\
\hline & & & Xunyi & Xingping & \\
\hline Bramley $^{\mathrm{a}}$ & 9 & $\ldots$ & $\ldots$ & $\ldots$ & $\ldots$ \\
\hline $\operatorname{Cox}^{\mathrm{a}}$ & 8 & $\ldots$ & $\ldots$ & $\ldots$ & $\ldots$ \\
\hline Worcester ${ }^{\mathrm{a}}$ & 9 & $\ldots$ & $\ldots$ & $\ldots$ & $\ldots$ \\
\hline Gala & 12 & 4 & 13 & 11 & $\ldots$ \\
\hline Elstar & $\ldots$ & $\ldots$ & 1 & 4 & $\ldots$ \\
\hline Fuji & $\ldots$ & $\ldots$ & 7 & 4 & $\ldots$ \\
\hline Qingguan & $\ldots$ & $\ldots$ & 4 & 6 & $\ldots$ \\
\hline Scab races & 5 (R2-R6) & $\ldots$ & $\ldots$ & $\ldots$ & 12 (R5-R7) \\
\hline Total & 43 & 4 & \multicolumn{2}{|c|}{50} & 12 \\
\hline
\end{tabular}

${ }^{a}$ Cultivars were planted next to each other in a mixture orchard.

Table 2. Amplified fragment length polymorphism (AFLP) primer pairs $\left(5^{\prime}\right.$ to $\left.3^{\prime}\right)$ used for screening isolates of Venturia inaequalis

\begin{tabular}{ll}
\hline Code & AFLP primer pairs and fluorescent labels \\
\hline $\mathrm{H}$ & GATGAGTCCTGAGTAAC + 6-FAM-AGACTGCGTACCAATTCAT \\
$\mathrm{K}$ & GATGAGTCCTGAGTAAC + NED-AGACTGCGTACCAATTCTG \\
$\mathrm{L}$ & GATGAGTCCTGAGTAAG + NED-AGACTGCGTACCAATTCTG \\
\hline
\end{tabular}

selected from each of two (United Kingdom) or three (China and India) cultivars within each country for inoculation studies to determine general virulence characteristic. These were to be tested in triplicate, once in each country; however, because of the lack of active sporulation and active growing (susceptible) leaves, the number of isolates actually used in inoculations was less than 80 in each region: 41, 47 , and 59 isolates were used in the United Kingdom, India, and China, respectively (Table 3). Most of the U.K. and Chinese isolates actually tested, except for a few, also were screened with the AFLP markers. Cv. Gala (highly susceptible) was used as a common cultivar in each country for testing; another cultivar was a popular local susceptible cultivar in each country (Cox in the United Kingdom, Black Ben Davis in India, and Qingguan in China). Both Cox and Black Ben Davis are highly susceptible to scab whereas Qingquan was moderately susceptible. Cvs. Fuji in China and Golden Delicious in India were included as two other highly susceptible cultivars popular locally. Cv. Saturn, which carries the $V f$ resistance gene, also was used in the United Kingdom.

In vitro production of conidia. Cellophane discs $(8 \mathrm{~cm}$ in diameter, $325 P$ cellulose) were soaked in reverse osmosis (RO) water for $20 \mathrm{~h}$ and then layered with filter paper in a glass petri dish, which then was filled with water, covered with aluminum foil, and sterilized in an autoclave. The sterile discs then were placed onto malt extract agar at $20 \mathrm{~g} \mathrm{liter}^{-1}$ in petri dishes. An Ultra-Turrax macerator was used to homogenize a small part of a $V$. inaequalis culture with $5 \mathrm{ml}$ of water for a few seconds. The homogenate $(200 \mu \mathrm{l})$ was pipetted onto a cellophane disc and spread evenly. The plates were sealed and incubated at $18^{\circ} \mathrm{C}(10 \mathrm{~h}$ of light and $14 \mathrm{~h}$ of dark) for 10 to 14 days. To harvest conidia, the cellophane disc was aseptically removed from each plate and placed in a sterile petri dish. A smaller disc was cut from it, mixed with $5 \mathrm{ml}$ of water, and agitated. Conidial concentrations were adjusted as necessary. The remainder of the cellophane was left to dry in a laminar flow cabinet and the dish was sealed with Parafilm and stored in a freezer $\left(-20^{\circ} \mathrm{C}\right)$ until needed.

Inoculation and disease assessment. Virulence testing at all three sites followed the same protocol. One- or two-year-old grafted plants were raised in plastic pots. Before inoculations, a small tag was tied to the youngest unrolled leaf on each growing shoot. The inocula for different isolates all were prepared at 2 to $3 \times 10^{5}$ conidia $\mathrm{ml}^{-1}$. Each isolate was inoculated onto three plants of each cultivar using a 50-mlcapacity atomizer. The inoculated shoots immediately were covered with watersprayed transparent polythene bags. A water-soaked piece of cotton wool tied 
with thin wire was wrapped around the stem of the branch within the polythene bags to maintain high humidity. Plants were kept in a polythene tunnel or glasshouse compartment; polythene bags were removed after $48 \mathrm{~h}$.

Disease (presence of lesions with or without sporulation) was visually recorded 14 and 28 days after inoculation on five leaves on each inoculated shoot: the tagged leaf and two leaves above (younger) and below (older) the tagged leaf. If necessary, sporulation was confirmed by examination with a microscope. At each site, inoculation was carried out on several occasions.

Statistical analysis. AFLP data. AFLP data were initially analyzed using cluster analysis (unweighted pair group method with arithmetic mean [UPGMA] algorithm) based on Jaccard's similarity coefficient using Genstat (25). Then, analysis of molecular variance (AMOVA) was conducted (using the Arlequin software, version 3.11) (8) to test each specific hypothesis regarding fungal population differentiation in relation to their geographical and host origins. Finally, permutation analysis was carried out to compare within-population fungal variability.

Several hypotheses on population differentiation in $V$. inaequalis were tested by AMOVA at a two-hierarchical level (country [China and the United Kingdom] and cultivars within country). Separate AMOVA at a single hierarchical level also was carried out to test population differences between two regions in China, between cultivars within China or the United Kingdom, and between Gala isolates from China, India, and the United Kingdom. The significance of differences between fungal populations was assessed based on 10,100 permutations. In addition, pairwise comparisons between fungal populations were done using AMOVA; this is essentially the same as testing the significance of the pairwise $\mathrm{F}_{\mathrm{ST}}\left(\right.$ or $\theta_{\mathrm{P}}$ ), calculated as the ratio between the "betweenpopulation" and "total" covariance components estimated from AMOVA. Statistical significance of each pairwise population difference was based on 1,023 permutations. Cluster analysis with UPGMA was carried to produce a tree depicting the observed genetic differences between fungal populations using GDA software (10); genetic distance $(d)$ between pairs of populations was calculated as $d=$ $-\ln \left(1-F_{S T}\right)$, where $F_{S T}$ is as defined above.

Within-population variability was assessed through permutation analysis. For example, to compare within-population variability between $x$ number of Chinese isolates and $y$ number of the U.K. isolates, the Jaccard's similarity coefficient was calculated for all pairs of these isolates. Then, $x$ number of isolates was sampled randomly from all the isolates $(x+y)$ without replacement. Next, average pairwise-similarity coefficient (ASC) for all the pairs of isolates within the $x$ randomly sampled isolates was calculated. This sampling for ASC calculation was repeated 10,000 times. Finally, these 10,000 ASC values were ranked and compared with the observed ASC value for Chinese isolates to estimate the significance level. In addition, the coefficient of variation $(\mathrm{CV})$ in the pairwise similarity values was calculated for the observed data as well as for each randomly drawn group. The average ASC and its CV summarize the overall similarity within the group as well as variability between isolates within the group. Similarly, this analysis was repeated to test the extent of similarity between U.K. isolates.

Virulence data. An inoculation of one single isolate against a particular cultivar was considered to be successful (i.e., compatible) only if it resulted in sporulating lesions because only this could lead to a continuation of an epidemic under natural conditions, thereafter simply referred to as infection. The overall proportion of infection of a given cultivar by a group of isolates was used to represent the group virulence characteristics against this particular cultivar.

A standard Normal approximation for two-sample tests of binomial data (1) was used to analyze the data from inoculation studies. This test was used to compare (i) proportion of isolates from the same coun- try that infected two cultivars and (ii) proportion of isolates from two countries that infected the same cultivar. This test was carried out only for data from the same testing site because of possible differences in experimental conditions between testing sites. No attempts were made to apply the test to compare proportions on a single cultivar by isolates from individual cultivars from each country because of small number of isolates used.

\section{RESULTS}

Molecular variation. Initially, a total of 146 isolates was screened for AFLP markers. However, there were 24, 16, and 10 isolates that failed to generate reliable AFLP results for the $\mathrm{H}, \mathrm{K}$, and L (Table 2) markers, respectively. Thus, only 109 isolates (38 from the United Kingdom, 50 from China, 4 from India, and 17 with known race types) were included in population comparisons. For the three marker sets, there was a total of 239 polymorphic AFLP bands, with 97, 84, and 58 different polymorphic bands for primer sets $\mathrm{H}, \mathrm{K}$, and L, respectively.

Cluster analysis of individual isolates showed that there was some degree of separation between Chinese and U.K. isolates, though it was not uncommon for isolates from the United Kingdom and China to be in the same clusters. There were no clear delineation of groups (clusters) based on location. There were no clear indications of separations of isolates from different cultivars. The 17 isolates with known race types were scattered throughout the cluster diagram, with no apparent relationships to race type or to other isolates in relation to their origin.

AMOVA analysis at a two-hierarchical level indicated significant $(P<0.05)$ differences between Chinese and U.K. populations, between populations from different cultivars within China and the United Kingdom $(P<0.0001)$, and between isolates from the same cultivar $(P<0.0001)$; these three sources of variability accounted for $15.5,5.7$, and $78.8 \%$ of the total variation, respectively. The overall significant difference between cultivars within China

Table 3. Number of isolates of Venturia inaequalis used in the inoculation study and their origins

\begin{tabular}{|c|c|c|c|c|c|c|c|c|c|}
\hline \multirow[b]{3}{*}{ Isolate origin } & \multicolumn{9}{|c|}{ Testing sites and cultivars used at each ${ }^{a}$} \\
\hline & \multicolumn{3}{|c|}{ India } & \multicolumn{3}{|c|}{ China } & \multicolumn{3}{|c|}{ United Kingdom } \\
\hline & Gala & Black Ben Davis & Golden Delicious & Gala & Fuji & Qingguan & Gala & Cox & Saturn \\
\hline \multicolumn{10}{|l|}{ India } \\
\hline Gala & $2(2)$ & $2(2)$ & $2(2)$ & $10(8)$ & $10(4)$ & $10(0)$ & $\ldots$ & $7(1)$ & $7(0)$ \\
\hline Black Ben Davis & $2(1)$ & $2(1)$ & $2(1)$ & $\ldots$ & & $\ldots$ & $\ldots$ & $\ldots$ & $\ldots$ \\
\hline Golden Delicious & $2(2)$ & $2(2)$ & $2(2)$ & $6(5)$ & $6(1)$ & $6(0)$ & $\ldots$ & $\ldots$ & $\ldots$ \\
\hline \multicolumn{10}{|l|}{ China } \\
\hline Gala & $9(3)$ & $9(0)$ & $9(3)$ & $8(7)$ & $8(5)$ & $8(0)$ & $7(3)$ & $7(0)$ & $7(0)$ \\
\hline Fuji & $8(3)$ & $8(0)$ & $8(3)$ & $9(6)$ & $9(4)$ & $9(0)$ & $9(5)$ & $9(0)$ & $9(0)$ \\
\hline Qingguan & $7(2)$ & $7(0)$ & $7(4)$ & $6(5)$ & $6(1)$ & $6(2)$ & $8(5)$ & $8(0)$ & $8(0)$ \\
\hline \multicolumn{10}{|l|}{ United Kingdom } \\
\hline Gala & $9(1)$ & $9(1)$ & $9(2)$ & $10(6)$ & $10(5)$ & $10(0)$ & $\ldots$ & $10(2)$ & $10(0)$ \\
\hline Cox & $8(0)$ & $8(0)$ & $8(2)$ & $10(5)$ & $10(2)$ & $10(0)$ & $\ldots$ & $\ldots$ & $\ldots$ \\
\hline
\end{tabular}

${ }^{a}$ Numbers in parentheses are the number of isolates that caused sporulating lesions. 
and the United Kingdom was due to the differences between isolates from the four U.K. cultivars: separate AMOVA at a single hierarchical level indicated no significant differences among isolates from the Chinese cultivars $(P>0.05)$ but did indicate significant differences among isolates from the U.K. cultivars $(P<0.0001)$. Similarly, separate AMOVA showed no significant differences between isolates from two Chinese regions $(P>0.05)$ but did show significant differences among fungal isolates from Gala from China, India, and the United Kingdom $(P<0.0001)$. There also were significant $(P<0.01)$ differences among isolates from the three U.K. cultivars in the same orchard.

There were no significant pairwise differences among isolates from the four
Chinese cultivars (Table 4). All pairwise differences between U.K. and Chinese isolates were statistically significant. Apart from the comparison between isolates from Cox and Bramley, all other pairwise differences between U.K. isolates were significant. As a group, the four Indian isolates from Gala were significantly different from all other populations. Races 6 and 7 were significantly different from Chinese isolates as well as the U.K. Worcester and Gala isolates. A tree depicting the overall differences among these 12 populations is shown in Figure 1.

Within-population variability in U.K. and Chinese isolates was studied via a random permutation test. The observed ASC value for the 50 Chinese isolates was 0.516 , com- pared with the maximum ASC value of 0.478 from the 10,000 permutation values, indicating that Chinese isolates, as a group, were much more homogeneous than expected $(P<0.0001)$. This was further confirmed by the less-than-expected $(P=$ $0.005) \mathrm{CV}$ of pairwise similarity for the Chinese isolates. In contrast, the observed ASC (0.340) for 38 U.K. isolates was only just greater than the 13th smallest ASC of the 10,000 permutation values, indicating that U.K. isolates were much more diverse $(P=0.0013)$ than expected.

There were no significant differences in within-population variability between isolates from the two regions (Xingping and Xunyi) or from the four cultivars in China. In contrast, within-population variability varied significantly between U.K.

Table 4. Estimated pairwise $F_{S T}$ values from the analysis of molecular variance of pairs of Venturia inaequalis populations ${ }^{\mathrm{a}}$

\begin{tabular}{|c|c|c|c|c|c|c|c|c|c|c|c|}
\hline \multirow[b]{2}{*}{ Population $^{\mathrm{b}}$} & \multicolumn{4}{|c|}{ China } & \multicolumn{4}{|c|}{ United Kingdom } & \multicolumn{3}{|c|}{ Others } \\
\hline & Gala & Fuji & Elstar & Qingguan & Bramley & Cox & Gala & Worcester & Race 6 & Race 7 & Indian Gala \\
\hline \multicolumn{12}{|l|}{ China } \\
\hline Gala (24) & & $\ldots$ & $\ldots$ & $\ldots$ & $\ldots$ & $\ldots$ & $\ldots$ & $\ldots$ & $\ldots$ & $\ldots$ & $\ldots$ \\
\hline Fuji (11) & 0.004 & $\ldots$ & $\ldots$ & $\ldots$ & $\ldots$ & $\ldots$ & $\ldots$ & $\ldots$ & $\ldots$ & $\ldots$ & $\ldots$ \\
\hline Elstar (5) & 0.002 & 0.006 & & $\ldots$ & $\ldots$ & $\ldots$ & $\ldots$ & $\ldots$ & $\ldots$ & $\ldots$ & $\ldots$ \\
\hline Qingguan' (10) & 0.006 & 0.008 & 0.008 & $\ldots$ & $\ldots$ & $\ldots$ & $\ldots$ & $\ldots$ & $\ldots$ & $\ldots$ & $\ldots$ \\
\hline \multicolumn{12}{|l|}{ United Kingdom } \\
\hline Bramley (9) & $0.189 * *$ & $0.149 * *$ & $0.182 *$ & $0.183 * *$ & $\ldots$ & $\ldots$ & $\ldots$ & $\ldots$ & $\ldots$ & $\ldots$ & $\ldots$ \\
\hline $\operatorname{Cox}(8)$ & $0.292 * *$ & $0.255^{* * *}$ & $0.304 * *$ & $0.292 * *$ & 0.031 & $\ldots$ & $\ldots$ & $\ldots$ & $\ldots$ & $\ldots$ & $\ldots$ \\
\hline Gala (12) & $0.174 * *$ & $0.144 * *$ & $0.172 * *$ & $0.163 * *$ & $0.087 * *$ & $0.207 * *$ & $\ldots$ & $\ldots$ & $\ldots$ & $\ldots$ & $\ldots$ \\
\hline Worcester (9) & $0.265^{* *}$ & $0.213^{* *}$ & $0.256^{* *}$ & $0.252 * *$ & $0.075^{*}$ & $0.174 * *$ & $0.154 * *$ & $\ldots$ & $\ldots$ & $\ldots$ & $\ldots$ \\
\hline \multicolumn{12}{|l|}{ Others } \\
\hline Race 6 (6) & $0.193 * *$ & $0.146^{* *}$ & $0.168^{*}$ & $0.175^{* *}$ & 0.020 & 0.036 & $0.073^{*}$ & $0.139 * *$ & $\ldots$ & $\ldots$ & $\ldots$ \\
\hline Race 7 (6) & $0.252 * *$ & $0.221 * *$ & $0.240 *$ & $0.246^{* *}$ & 0.043 & 0.025 & 0.160 ** & $0.177 * *$ & 0.008 & $\ldots$ & $\ldots$ \\
\hline Indian Gala (4) & $0.223 * *$ & $0.191 * *$ & $0.251^{*}$ & $0.201 * *$ & $0.142 *$ & $0.255^{* *}$ & $0.162 * *$ & $0.262 * *$ & $0.131 *$ & $0.194 *$ & $\ldots$ \\
\hline Other races (5) & $0.132 * *$ & $0.074 *$ & 0.077 & $0.105^{*}$ & 0.072 & $0.179 *$ & 0.020 & $0.118 * *$ & 0.015 & 0.098 & $0.111^{*}$ \\
\hline
\end{tabular}

a Significance: * and ** indicate significant at the 5 and $1 \%$ level, respectively; significance was evaluated only at the 5\% level based on 1,023 permutations using the Arlequin software (8).

${ }^{b}$ Number in parentheses is the number of isolates included in the comparison.

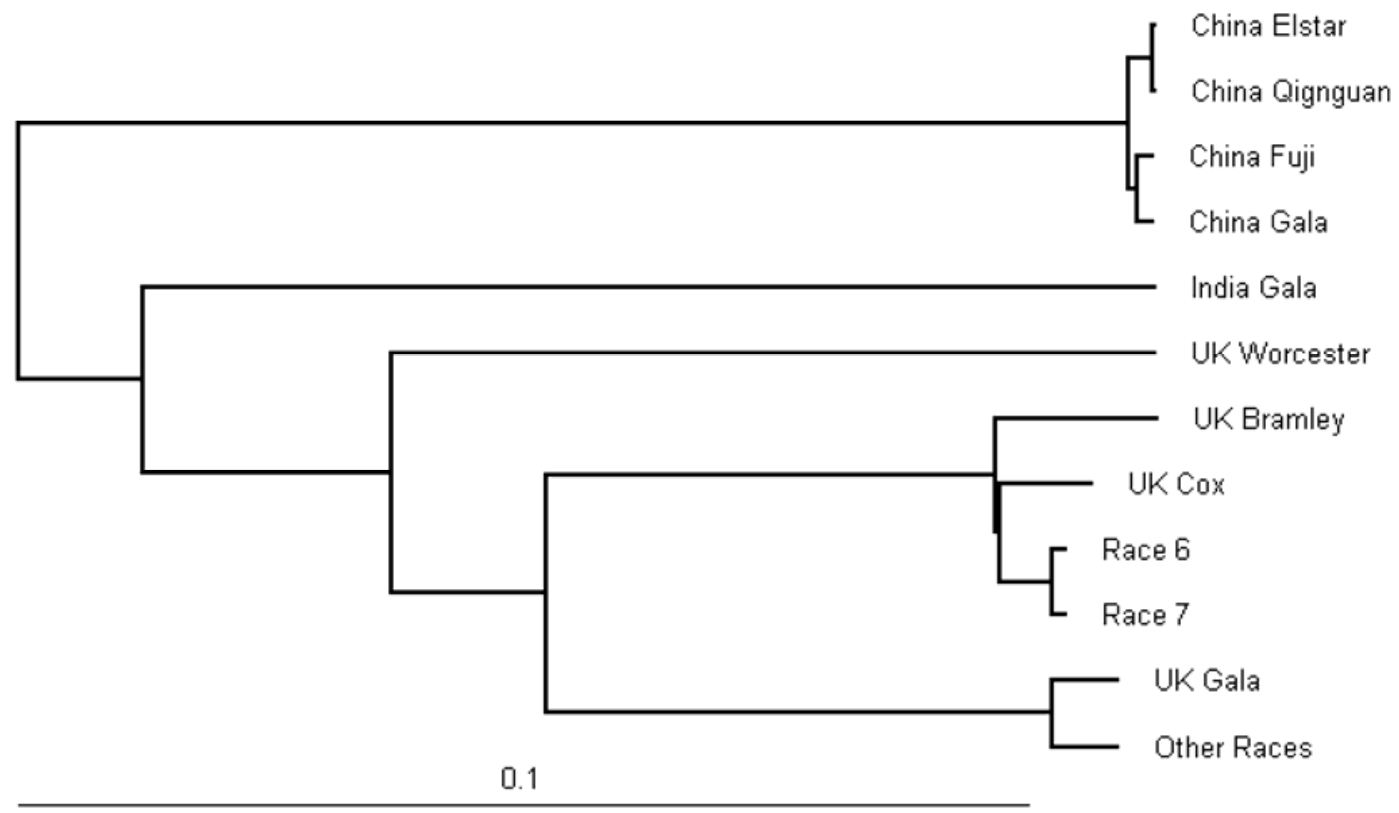

Fig. 1. Tree derived from a cluster analysis of amplified fragment length polymorphism data using the unweighted pair group method with arithmetic mean depicting the observed differences between populations of Venturia inaequalis using the GDA software (10); genetic distance $(d)$ between pairs of populations was calculated as $d=-\ln \left(1-F_{S T}\right)$, where $F_{S T}$ is calculated as the ratio between the "between-population" and "total" covariance components estimated from analysis of molecular variance. 
isolates from the four cultivars. Isolates from Gala $(P=0.0003)$ and Worcester $(P$ $=0.0167)$ were more homogeneous than expected but isolates from Cox were more diverse than expected $(P=0.0005)$. Variability among Bramley isolates did not deviate significantly from the expected. None of the CV values for pairwise similarity values was significantly less or greater than expected. For those isolates from Gala, only the isolates from China were more homogeneous $(P<0.0075)$ than expected.

Virulence testing. Inoculation in India. For all the isolates tested (17, 6, and 24 isolates from the United Kingdom, India, and China, respectively), regardless of the isolate origin (cultivar or country), several isolates could infect Gala and Golden Delicious, except that none of the U.K. isolates from Cox infected Gala (Table 3). Of the 24 Chinese isolates, 8 and 10 infected Gala and Golden Delicious, respectively, which was significantly $(P<0.001)$ greater than the proportion of infection on local cv. Black Ben Davis: none of the Chinese isolates infected this cultivar (Table 3 ). The proportion of infection of the three cultivars by the 17 U.K. isolates was not statistically $(P>0.05)$ different: there were only 1,1 , and 4 U.K. isolates that infected Gala, Black Ben Davis, and Golden Delicious, respectively. Five of the six Indian isolates infected Gala, Golden Delicious, or Black Ben Davis (Table 3). The proportion of infection by the Indian isolates was significantly $(P<0.05)$ greater than that achieved by either the U.K. or Chinese isolates on each of the three cultivars tested.

Inoculation in China. Of the isolates tested (20, 16, and 23 isolates from the United Kingdom, India, and China, respectively), regardless of the isolate origin, many isolates successfully infected Gala and Fuji. Of the 20 U.K. isolates, 7 and 11 infected Fuji and Gala, respectively, which was significantly $(P<0.001)$ greater than the proportion of infection on cv. Qingguan: none of the U.K. isolates infected this cultivar (Table 3 ). Of the 16 Indian isolates, more $(P<0.01)$ isolates infected Gala $(n=13)$ than Fuji $(n=5)$ which, in turn, were more $(P<0.001)$ than those infected Qingguan $(n=0)$. Several Chinese isolates from Gala and Fuji infected both cultivars but all failed to infect Qingguan. Isolates originating from Qingguan could infect all three cultivars (Table 3 ). Overall, fewer $(P<0.01)$ Chinese isolates infected Qingguan $(n=2)$ than Fuji $(n=10)$ which, in turn, were fewer $(P<0.05)$ than those infected Gala $(n=18)$. There were no significant $(P>0.05)$ differences in the proportion of infection between isolates from three countries on each of the three cultivars tested.

Inoculation in the United Kingdom. Because of the lack of active growing shoots, only 10 U.K. isolates from Gala were in- oculated against Cox and Saturn; two of the isolates infected Cox (Table 3). Only seven Indian isolates from Gala were inoculated against Cox and Saturn, of which only one isolate infected Cox. A total of 13 out of 24 Chinese isolates infected Gala, significantly $(P<0.001)$ more than Cox or Saturn; none of the Chinese isolates infected the two cultivars (Table 3 ). As a group, more $(P<0.05)$ U.K. isolates infected Cox than Chinese isolates.

\section{DISCUSSION}

We have compared genetic variability between $V$. inaequalis isolates sampled from a limited number of cultivars from two different continents. The U.K. and Chinese populations differed significantly based on neutral molecular markers. Furthermore, inoculation of apple cultivars suggested existence of variability in the overall fungal population virulence characteristics between isolates from China, India, and the United Kingdom.

As a group, Chinese isolates differed significantly from U.K. isolates. Furthermore, Chinese isolates were significantly more homogeneous than U.K. isolates. There were no significant differences between isolates originating from different cultivars or from two counties in Shaanxi Province, China. In contrast, there were significant genetic differences between isolates originating from different cultivars in the United Kingdom. The genetic diversity in $V$. inaequalis populations has been determined for isolates sampled in several European countries based on molecular markers $(29,31)$. The diversity within each population in Europe was high, suggesting frequent short-distance gene flow within the population. However, dispersal over long distances also appears to occur because the extent of population relatedness appeared to be linearly related to geographical distances between populations (31).

The lack of genetic differentiation between these Chinese isolates, compared with the U.K. isolates, may be due to the relatively short history of apple cultivation in the region. In China, the traditional area of apple production is in northeast China and apple production in Shaanxi expanded only in the late 1980 s, replacing large areas of annual crops in a move intended to reduce soil erosion. This region is more than $1,500 \mathrm{~km}$ from the traditional apple production region and, thus, there may be a very limited gene flow from the traditional production region to Shaanxi. Further research is needed to confirm this. The history of cultivation in Shaanxi may have been too short for sufficient fungal adaptation to the cultivars grown in this region to take place, despite selection pressure exerted by cultivars in the region as shown by the considerable differences in host resistance or susceptibility in the inoculation results.

The U.K. isolates from different cultivars as well as their within-population variability differed significantly. This is particularly surprising because the isolates originating from Cox, Bramley, and Worcester were sampled from the same orchard where these cultivars were planted in adjacent rows. Isolates from Gala and Worcester were less diverse than expected in comparison with isolates from other cultivars. Isolates from Cox were much more diverse than expected. These results may be interpreted on the basis of several evolutionary forces acting on the pathogen. First, different cultivars may have exerted significant differential selection pressure on $V$. inaequalis. The selection imposed by Worcester might be the most stringent, resulting in the least diverse fungal population. Equally probable is that the fungus may have overcome resistance genes relatively recently in Worcester compared with the other two cultivars (though well before the establishment of this orchard because this cultivar has been known to be susceptible to scab for a long time). Thus, the lack of genetic variability in isolates from Worcester may largely reflect a founder effect. This phenomenon also was observed in a $V$. inaequalis population that recently overcame the $V f$ resistance gene $(12,29)$. By the same reasoning, resistance in Cox might have been overcome the earliest. Second, sexual recombination between isolates originating from different cultivars may not have taken place as frequently as expected. If there was freely occurring annual recombination between all isolates from different cultivars, these significant differences in "neutral" molecular markers between isolates from different cultivars would not be likely to occur. Thus, sexual reproduction most likely appears to be taking place between isolates with similar virulence backgrounds (i.e., from the same cultivars). This could be due to two possible reasons. First, ascospore progenies derived from crosses between isolates of similar virulence may be more virulent than those progenies from crosses between isolates of different virulence background. If virulence to a particular cultivar is mediated by several genes, sexual reproduction between isolates with very different virulence background is likely to result in break-up of those previously assembled virulence genes to a particular host, leading to an overall loss of virulence in progeny ascospores. Second, ascospores are expected to result from crosses between isolates that infected the same leaf. Research currently is underway to determine whether mating also could take place between isolates on different leaves when they are in contact with each other on the ground.

It is interesting to note that isolates of races 6 and 7 as a group were very similar to each other and were close to the isolates from Cox and Bramley but differed significantly from Asian isolates. This significant differentiation of races 6 and 7 from 
the Asian isolates could well be explained by the fact that both races are from Europe. The closeness among these two races may be attributed to their similar virulence characteristics. They differ in that race 6 is able to infect only some cultivars carrying $V f$ descended from $M$. floribunda 821 but race 7 can infect all such cultivars descended from $M$. floribunda 821. This difference is attributed to the original $V f$ resistance in $M$. floribunda 821 consisting of at least two different resistance genes, $V f$ and $V f h$; race 6 can overcome only $V f$ but race 7 can overcome both. Indeed, reduced genetic diversity among isolates capable of breaking the $V f$ resistance in cv. Judeline has been observed (12): Judeline can be infected by both races 6 and $7(2,16)$. In addition, race 6 can overcome $V g$ and race 7 cannot (2). None of the isolates collected from commercial orchards and tested here were able to infect Saturn, even though breakdown of this resistance has been reported in the United Kingdom and elsewhere $(22,26)$.

There were noticeable differences in the virulence of isolates of $V$. inaequalis toward cultivars in each region. Far fewer Chinese isolates succeeded in infecting the U.K. and Indian local susceptible cultivars (Cox and Black Ben Davis) than the other two more widely planted cultivars (Gala and Golden Delicious). This may suggest that locally susceptible cultivars possess effective resistance genes to which foreign isolates have not been exposed, although these resistances may have been overcome already by isolates from the same region. This type of "hidden" resistance may be expected to be more effective against foreign isolates with less heterogeneous genetic backgrounds, such as the Chinese isolates used in the present study. This kind of hidden resistance in susceptible cultivars has been demonstrated in several inoculation studies $(14,15,27)$. The local Chinese cv. Qinguan appeared to possess very effective resistance genes against isolates regardless of their origin. Scab severity and subsequent sporulation are generally known to be less on Qinguan in China.

Breeding apple cultivars with durable resistance to scab remains the ultimate goal for managing this disease. Current breeding efforts focus on pyramiding major $R$ genes from different sources via the marker-assisted selection approach (4$6,13,18,23,24,32)$. In addition to incorporating these major $R$ genes, some effort also has been spent on utilizing partial (or polygenic) resistance often found in old germplasm (17). This study shows that locally adapted susceptible cultivars also may possess effective resistance against foreign isolates. Further research is needed to confirm this.

\section{ACKNOWLEDGMENTS}

This research was funded by the European Union (contract number: ICA4-CT-2001-10001). We thank L. Parisi of UERI of Gotheron, INRA, France for providing 15 isolates of races 5 to 7 of $\mathrm{V}$. inaequalis.

\section{LITERATURE CITED}

1. Arimitage, P., and Berry, G. 1994. Statistical Methods in Medical Research. Blackwell Science, Oxford.

2. Benaouf, G., and Parisi, L. 2000. Genetics of host-pathogen relationships between Venturia inaequalis races 6 and 7 and Malus species. Phytopathology 90:236-242.

3. Berrie, A. M., and Xu, X.-M. 2003. Managing apple scab and powdery mildew using Adem. Int. J. Pest Manage. 49:243-250.

4. Bus, V. G. M., Laurens, F. N. D., van de Weg, W. E., Rusholme, R. L., Rikkerink, E. H. A., Gardiner, S. E., Bassett, H. C. M., Kodde, L. P., and Plummer, K. M. 2005. The Vh8 locus of a new gene-for-gene interaction between Venturia inaequalis and the wild apple Malus sieversii is closely linked to the Vh2 locus in Malus pumila R12740-7A. New Phytol. 166:1035-1049.

5. Bus, V. G. M., Rikkerink, E. H. A., van de Weg, W. E., Rusholme, R. L., Gardiner, S. E., Bassett, H. C. M., Kodde, L. P., Parisi, L., Laurens, F. N. D., Meulenbroek, E. J., and Plummer, K. M. 2005. The Vh2 and Vh4 scab resistance genes in two differential hosts derived from Russian apple R12740-7A map to the same linkage group of apple. Mol. Breed. 15:103-116.

6. Calenge, F., Faure, A., Goerre, M., Gebhardt, C., Van de Weg, W. E., Parisi, L., and Durel, C. E. 2004. Quantitative trait loci (QTL) analysis reveals both broad-spectrum and isolatespecific QTL for scab resistance in an apple progeny challenged with eight isolates of Venturia inaequalis. Phytopathology 94:370-379.

7. Durel, C. E., Parisi, L., Laurens, F., Van de Weg, W. E., Liebhard, R., and Jourjon, M. F. 2003. Genetic dissection of partial resistance to race 6 of Venturia inaequalis in apple. Genome 46:224-234.

8. Excoffier, L., and Schneider, S. 2005. Arlequin ver. 3.0: an integrated software package for population genetics data analysis. Evol. Bioinf. Online 1:47-50.

9. Gao, Z. S., and van de Weg, W. E. 2006. The $V$ - $f$ gene for scab resistance in apple is linked to sub-lethal genes. Euphytica 151:123-133.

10. Genetic Data Analysis: Computer Program for the Analysis of Allelic Data, Version 1.1. http://www.eeb.uconn.edu/people/plewis/soft ware.php.

11. Gessler, C., Patocchi, A., Sansavini, S., Tartarini, S., and Gianfranceschi, L. 2006. Venturia inaequalis resistance in apple. Crit. Rev. Plant Sci. 25:473-503.

12. Guerin, F., and Le Cam, B. 2004. Breakdown of the scab resistance gene $V f$ in apple leads to a founder effect in populations of the fungal pathogen Venturia inaequalis. Phytopathology 94:364-369.

13. Gygax, M., Gianfranceschi, L., Liebhard, R., Kellerhals, M., Gessler, C., and Patocchi, A. 2004. Molecular markers linked to the apple scab resistance gene $V b j$ derived from Malus baccata Jackii. Theor. Appl. Genet. 109:17021709.

14. Hernàndez Castillo, F. D., Parisi, L., and Lespinasse, Y. 1994. Heredabilidad del factor de avirulencia de una cepa de Venturia inaequalis (Cke.) Wint. Sobre el cultivar de manzano (Malus $\times$ domestica Borkh.) Golden Delicious. Rev. Mexi. Fitopatol. 12:31-34.

15. Koch, T., Kellerhals, M., and Gessler, C. 2000. Virulence pattern of Venturia inaequalis field isolates and corresponding differential resistance in Malus $\times$ domestica. J. Phytopathol. 148:357-364.

16. Lateur, M., Wagemans, C., and Populer, C. 1999. Evaluation of fruit tree genetic resources as sources of polygenic scab resistance in ap- ple breeding. Acta Hortic. 484:35-42.

17. Lateur, M., Lefrancq, B., and Parisi, L. 2002. First evidence of the breakdown in Belgium of the scab resistance conferred by the $V f$ gene. Meded. Fac. Landbouwwet. Univ. Gent 67:135-143.

18. Liebhard, R., Koller, B., Patocchi, A., Kellerhals, M., Pfammatter, W., Jermini, M., and Gessler, C. 2003. Mapping quantitative field resistance against apple scab in a 'Fiesta' $\times$ 'Discovery' progeny. Phytopathology 93:493-501.

19. MacHardy, W. E. 1996. Apple scab: biology, epidemiology, and management. American Phytopathological Society, St. Paul, MN.

20. MacHardy, W. E. 2000. Current status of IPM in apple orchards. Crop Prot. 19:801-806.

21. MacHardy, W. E., Gadoury, D. M., and Gessler, C. 2001. Parasitic and biological fitness of Venturia inaequalis: relationship to disease management strategies. Plant Dis. 85:1036-1051.

22. Parisi, L., Lespinasse, Y., Guillaumes, J., and Kruger, J. 1993. A new race of Venturia inaequalis virulent to apples with resistance due to the $V f$ gene. Phytopathogy 83:533-537.

23. Patocchi, A., Bigler, B., Koller, B., Kellerhals, M., and Gessler, C. 2004. $\operatorname{Vr}(2)$ : a new apple scab resistance gene. Theor. Appl. Genet. 109:1087-1092

24. Patocchi, A., Walser, M., Tartarini, S., Broggini, G. A. L., Gennari, F., Sansavini, S., and Gessler, C. 2005. Identification by genome scanning approach (GSA) of a microsatellite tightly associated with the apple scab resistance gene $V m$. Genome 48:630-636.

25. Payne, R., ed. 2002. The Guide to GenStat Release 6.1-Part 2: Statistics. VSN International, Oxford.

26. Roberts, A. L., and Crute, I. R. 1994. Apple scab resistance from Malus floribunda 821 (Vf) is rendered ineffective by isolates of Venturia inaequalis from Malus floribunda. Norw. J. Agric. Sci. (Suppl.) 17:403-406.

27. Sierotzki, H., and Gessler, C. 1998. Inheritance of virulence of Venturia inaequalis toward Malus x domestica cultivars. J. Phytopathol. 146:509-514.

28. Tartarini, S., Gennari, F., Pratesi, D., Palazzetti, C., Sansavini, S., Parisi, L., Fouillet, A., Fouillet, V., and Durel, C. 2004. Characterization and genetic mapping of a major scab resistance gene from the old Italian cultivar 'Durello di Forli'. Acta Hortic. 663:129-134.

29. Tenzer, I., and Gessler, C. 1997. Subdivision and genetic structure of four populations of Venturia inaequalis in Switzerland. Eur. J. Plant Pathol. 103:565-571.

30. Tenzer, I., and Gessler, C. 1999. Genetic diversity of Venturia inaequalis across Europe. Eur. J. Plant Pathol. 105:545-552.

31. Tenzer, I., degli Ivanissevich, S., Morgante, M., and Gessler, C. 1999. Identification of microsatellite markers and their application to population genetics of Venturia inaequalis. Phytopathology 89:748-753.

32. Vinatzer, B. A., Patocchi, A., Tartarini, S., Gianfranceschi, L., Sansavini, S., and Gessler, C. 2004. Isolation of two microsatellite markers from BAC clones of the $V f$ scab resistance region and molecular characterization of scabresistant accessions in Malus germplasm. Plant Breed. 123:321-326.

33. Williams, E. B., and Kuc, J. 1969. Resistance in Malus to Venturia inaequalis. Annu. Rev. Phytopathol. 7:223-246.

34. Xu, M. L., and Korban, S. S. 2002. A cluster of four receptor-like genes resides in the Vf locus that confers resistance to apple scab disease. Genetics 162:1995-2006.

35. Xu, M. L., and Korban, S. S. 2004. Somatic variation plays a key role in the evolution of the $V f$ gene family residing in the Vf locus that confers resistance to apple scab disease. Mol. Phylogenet. Evol. 32:57-65. 